CLINICAL STUDY

\title{
Growth hormone-binding protein is directly and IGFBP-3 is inversely associated with risk of female breast cancer
}

\author{
Kalliopi Pazaitou-Panayiotou*, Theodore Kelesidis ${ }^{1, *}$, Iosif Kelesidis ${ }^{1, *}$, Athina Kaprara, Jennifer Blakeman ${ }^{1}$, \\ Iraklis Vainas, Aris Mpousoulegas ${ }^{2}$, Catherine J Williams ${ }^{1}$ and Christos Mantzoros ${ }^{1}$ \\ Department of Endocrinology-Endocrine Oncology, Theagenio Cancer Hospital, Thessaloniki, Greece, ${ }^{1}$ Division of Endocrinology, Diabetes and Metabolism, \\ Beth Israel Deaconess Medical Center, 330 Brookline Avenue, Stoneman 816, Boston, Massachusetts 02215, USA and ${ }^{2}$ Division of Surgery, Theageneio \\ Cancer Hospital, Thessaloniki, Greece \\ (Correspondence should be addressed to C S Mantzoros; Email: cmantzor@bidmc.harvard.edu)
}

*(K Pazaitou-Panayiotou, T Kelesidis and I Kelesidis contributed equally to this work)

\begin{abstract}
Objective: Several components of the GH and IGF systems have been implicated in the development of malignancies. All components of these hormonal systems have never been jointly evaluated in female breast cancer, and previous studies have not examined the role of IGF-binding proteins (IGFBP-4, IGFBP-6) or GH-binding protein (GHBP).

Design: Hospital-based case-control study.

Methods: In this sample of primarily postmenopausal women, we obtained serum measures of IGF-I, IGF-II, and binding proteins IGFBP-1, IGFBP-3, IGFBP-4, IGFBP-6, as well as GHBP, insulin, and leptin from 74 breast cancer cases and 76 control subjects.

Results: In crude analyses, we found lower age-standardized mean IGF-I, IGFBP-3, IGFBP-4, IGFBP-6, and higher IGFBP-1 and GHBP in breast cancer cases when compared with controls. Multivariate models mutually adjusted for other GH-IGF system components and classical breast cancer risk factors demonstrated an inverse association between IGFBP-3 and risk of breast cancer (odds ratio $(\mathrm{OR})=0.2$, $P<0.01)$ and a direct association between $\mathrm{GHBP}$ and disease risk $(\mathrm{OR}=3.3, P<0.01)$. No significant associations were detected in multivariate analyses among IGF-I, IGF-II or IGFBP-1, IGFBP-4, IGFBP-6 with risk of breast cancer, indicating that these factors may not have effects independent of and/or comparable with IGFBP-3 and GHBP.

Conclusions: These results support a protective role of IGFBP-3 and demonstrate for the first time an increased risk of breast cancer with higher GHBP, after accounting for variation in IGFs, IGFBPs, and classical breast cancer risk factors.
\end{abstract}

European Journal of Endocrinology 156 187-194

\section{Introduction}

The insulin-like growth factor (IGF) system is an intricate arrangement of growth factors (peptide hormones IGF-I and IGF-II), high affinity-binding proteins (IGFBP-1 to 6), as well as cell surface receptors, IGFBP proteases, and low affinity IGFBP-related proteins (1). This system plays a substantial role in human metabolism and cell proliferation, differentiation, and apoptosis, and thus has been proposed to be a determinant of risk for carcinoma, including breast cancer. Another closely related hormone that may be involved in the underlying mechanism is human growth hormone $(\mathrm{GH})$, which regulates IGF-I production mainly in the liver (2). GH, like IGF-I, which is usually bound in binary and ternary complexes with IGFBP-3, circulates in complexes with growth hormone-binding protein (GHBP). Since GH is secreted in a pulsatile fashion and displays considerable circadian variability, obtaining reliable measurements that reflect its integrated mean levels presents a challenge, and as such, the relationship between GH and cancer has not yet been adequately studied in epidemiology studies. However, serum concentrations of GHBP, which is the cleaved extracellular ligand-binding domain of GH receptors, may reflect the GH tissue receptor status $(3,4)$ and has been inversely associated with GH levels in several clinical conditions $(5,6)$.

Numerous epidemiologic studies have examined the association between components of the IGF system, in particular IGF-I and IGFBP-3, and female breast cancer (7-17). Most nested case-control studies have demonstrated an increased risk of premenopausal breast cancer with higher concentrations of IGF-I, but results have been mixed with respect to IGFBP-3, with reports of positive, negative, and no association. Studies with postmenopausal populations have tended to report no association between IGF-I or IGFBP-3 and risk of breast 
cancer. Strong theoretical bases suggest that the GH and IGF systems are important factors in tumor formation and proliferation (18-20). Specifically, IGF-I is known to induce cell proliferation in vitro, and IGFBPs have been shown to exert effects both dependent and independent of IGF function and may induce apoptosis (21). However, no prior study has examined the role of IGFBP-4 or IGFBP-6 in breast cancer, nor has any previous work included GHBP. Since the components of the GH and IGF systems are highly correlated, accurate measurement of each factor is imperative for both crude assessment and in mutually adjusted models to determine the central forces driving potential associations. Thus, we have simultaneously examined the role of circulating IGF-I, IGF-II, IGFBP-1, IGFBP-3, IGFBP-4, IGFBP-6, and GHBP, as well as insulin and leptin, accounting for effects of insulin resistance and fat mass respectively, in predicting risk of breast cancer in the context of a hospital-based case-control study consisting mostly of postmenopausal women.

\section{Materials and methods}

\section{Study subjects}

Study subjects were recruited during the 16-month period from September 2003 until February 2005, inclusive, from 81 consecutively diagnosed and histologically confirmed incident cases of female breast cancer at the department of surgery of the Theagenio Cancer Hospital in Greece. Of these cases, five women refused participation and two were excluded from the study on the basis of previous cancer at another site. The remaining 74 cases were enrolled in the study. Control subjects were identified among 83 women examined at the same site using identical diagnostic procedures and criteria in the context of a routine breast cancer prevention program but were free of breast cancer but may have been diagnosed with a benign lesion (such as fibroadenoma) from mammogram and/or biopsy tests. Of the potential controls, 76 consented to the study and met eligibility requirements. Study subjects responded to an interviewer-administered questionnaire covering demographic, anthropometric and clinical information, and fasting blood samples were taken by research assistants blinded to the case or control status of the 150 subjects and were subsequently stored on ice in Styrofoam containers at $-70{ }^{\circ} \mathrm{C}$. These samples were then shipped via overnight courier to the Beth Israel Deaconess Medical Center (Boston, MA, USA) for assay. Estrogen receptor (ER) and progesterone receptor (PR) status were identified immunohistochemically and/or biochemically. The study protocol was approved by the Theagenio Cancer Hospital Scientific Committee. All participants submitted written informed consent prior to enrolment in the study.

\section{Serum analysis}

Measurements of serum leptin (Diagnostic Systems Laboratories, Webster, TX, USA), insulin, IGF-I, IGF-II, IGFBP-1, IGFBP-3, IGFBP-4, IGFBP-6, and GHBP (LINCO, St Louis, MO, USA) were obtained for all samples from a single run of commercially available radioimmunoassays and ELISAs in the principal investigator's laboratory at the Beth Israel Deaconess Medical Center as described previously $(22,23)$. For the newly studied markers IGFBP-4, IGFBP-6, and GHBP, we report the following assay characteristics: IGFBP-4 had a sensitivity of $0.008 \mathrm{ng} / \mathrm{ml}$ and intraassay coefficient of variation (CV) values of $3.0-6.3 \%$, IGFBP-6 had a sensitivity of $1.1 \mathrm{ng} / \mathrm{ml}$ and intraassay CV values of $6.4-10.7 \%$, and GHBP had a sensitivity of $1.69 \mathrm{pmol} / \mathrm{l}$ and intraassay $\mathrm{CV}$ values of $3.2-5.6 \%$. Laboratory personnel conducting analyses were blinded to the case or control status of the samples.

\section{Statistical analysis}

Case and control groups were compared on demographic, somatometric, reproductive, and biochemical variables using standard $t$-tests or $\chi^{2}$-tests as appropriate. Log transformation was used on biochemical variables to achieve normal distribution. Nonparametric Mann-Whitney comparisons were also performed and yielded similar results (data not shown). Linear regression models were used to obtain agestandardized estimates of mean biochemical measures for case and control groups. Spearman unadjusted and partial correlations controlling for age and body mass index (BMI) were calculated between biochemical measures for control subjects. Risk of breast cancer was modeled using unconditional simple and multivariate logistic regression models of hormonal variables to produce crude and adjusted odds ratio (OR) estimates and 95\% confidence intervals. Biochemical markers were analyzed in tertile groups based on distributions of the control population. Reported $P$ values are two-sided, and a level of $\alpha=0.05$ was used to determine statistical significance. Analyses were conducted using the SAS statistical package (SAS, Version 8.2 for UNIX, SAS Institute, Cary, NC, USA).

\section{Results}

Characteristics of cases and controls are presented in Table 1. Among cases, tumor size ranged from 1 to $5 \mathrm{~cm}$ in diameter. At diagnosis, nine (12.2\%) of the cases had metastasis. Ductal carcinomas accounted for the majority of cases, with $58(78 \%)$ diagnoses. The remaining cases were $13(18 \%)$ lobular carcinomas and $3(4 \%)$ carcinomas otherwise differentiated (medullary, mucinous, papillary, and tubular carcinomas). When compared with control subjects, breast cancer patients were older, had higher age at first birth 
Table 1 Descriptive and biochemical variable measures by case and control status.

\begin{tabular}{|c|c|c|c|c|c|c|}
\hline \multirow[b]{2}{*}{ Variable } & \multicolumn{3}{|c|}{ All subjects } & \multicolumn{3}{|c|}{ Postmenopausal subjects } \\
\hline & Cases $(n=74)$ & Controls $(n=76)$ & $P$ value & Cases $(n=61)$ & Controls $(n=54)$ & $P$ value \\
\hline \multicolumn{7}{|l|}{ Case characteristics } \\
\hline \multicolumn{7}{|l|}{ Stage, $n(\%)$} \\
\hline I & $19(25)$ & & & $14(23)$ & & \\
\hline IIA,B & $32(43)$ & & & $24(39)$ & & \\
\hline IIIA,B,C & $14(19)$ & & & $14(23)$ & & \\
\hline Nodal positive, $n(\%)$ & $48(65)$ & & & $37(61)$ & & \\
\hline $\mathrm{ER}+/ \mathrm{PR}+, n(\%)$ & $40(54)$ & & & $33(57)$ & & \\
\hline $\mathrm{ER}+/ \mathrm{PR}-, n(\%)$ & $11(15)$ & & & $9(16)$ & & \\
\hline $\mathrm{ER}-/ \mathrm{PR}+, n(\%)$ & $3(4)$ & & & $2(3)$ & & \\
\hline $\mathrm{ER}-/ \mathrm{PR}-, n(\%)$ & $17(23)$ & & & $14(24)$ & & \\
\hline \multicolumn{7}{|l|}{ Descriptive } \\
\hline Age, mean (S.D.), years & $62.5(11.6)$ & $55.6(11.6)$ & $<0.01$ & $66.2(8.9)$ & $60.6(8.3)$ & $<0.01$ \\
\hline Height, mean (S.D.), $\mathrm{cm}$ & $158.2(5.6)$ & $159.3(5.9)$ & 0.18 & $158.0(5.8)$ & $158.6(5.4)$ & 0.49 \\
\hline BMI, mean (s.D.), $\mathrm{kg} / \mathrm{m}^{2}$ & $29.1(4.6)$ & $29.3(6.1)$ & 0.45 & $29.2(4.1)$ & $29.8(6.0)$ & 0.58 \\
\hline Age at menopause, mean (s.D.), years & $49.4(4.0)$ & $47.7(4.8)$ & 0.05 & $49.4(4.0)$ & $47.7(4.8)$ & 0.05 \\
\hline Age at first birth, mean (s.D.), years & $24.6(4.0)$ & $23.5(4.5)$ & 0.11 & $24.8(4.1)$ & $23.0(3.4)$ & 0.02 \\
\hline Nulliparous, $n(\%)$ & $7(9)$ & $5(7)$ & 0.76 & $5(8)$ & $4(7)$ & 1.00 \\
\hline Family history of breast cancer, $n(\%)$ & $5(7)$ & $4(5)$ & 1.00 & $2(3)$ & $2(4)$ & 1.00 \\
\hline Family history of cancer, $n(\%)$ & $20(27)$ & $17(23)$ & 0.70 & $19(31)$ & $13(24)$ & 0.41 \\
\hline \multicolumn{7}{|l|}{ Biochemical, age-standardized mean (S.E.) } \\
\hline Insulin (ng/ml) & $12.8(0.9)$ & $14.7(0.9)$ & 0.28 & $13.4(1.0)$ & $14.6(1.0)$ & 0.38 \\
\hline Leptin (ng/ml) & $10.9(0.6)$ & $11.4(0.6)$ & 0.84 & $11.4(0.7)$ & $11.5(0.7)$ & 0.55 \\
\hline IGF-I (ng/ml) & $126(13)$ & $138(12)$ & $<0.01$ & $105(13)$ & $115(14)$ & 0.06 \\
\hline IGF-II (ng/ml) & 1035 (32.5) & 1013 (33.2) & 0.40 & $1002(37)$ & $1018(40)$ & 0.96 \\
\hline IGFBP-1 (ng/ml) & $36.7(2.3)$ & $31.8(2.4)$ & $<0.01$ & $35.9(2.4)$ & $33.0(2.6)$ & $<0.01$ \\
\hline IGFBP-3 (ng/ml) & 4137 (134) & 4279 (135) & 0.02 & 3966 (152) & 4226 (162) & 0.37 \\
\hline IGFBP-4 (ng/ml) & $556(23)$ & $596(23)$ & $<0.01$ & $574(26)$ & $629(27)$ & $<0.01$ \\
\hline IGFBP-6 (ng/ml) & $518(31)$ & $599(30)$ & $<0.01$ & 547 (35) & $642(36)$ & $<0.01$ \\
\hline GHBP $(\mathrm{pmol} / \mathrm{l})$ & 1731 (89) & $1656(90)$ & 0.57 & $1805(94)$ & 1695 (100) & 0.02 \\
\hline
\end{tabular}

Abbreviations: S.D., standard deviation; BMI, body mass index; IGF, insulin-related growth factor; BP, binding protein.

(postmenopausal women only) and menopause (all women). Cases also had higher age-standardized IGFBP1 and GHBP and lower IGF-I, IGFBP-3, IGFBP-4, and IGFBP-6. Subjects did not differ significantly on other measured variables with respect to case or control status (Table 1).

Since substantial interrelationships are expected between the components of the GH and IGF systems, we present Spearman's correlations of age, BMI, hormones insulin and leptin, IGFs, IGFBPs, and GHBP among the 76 control subjects and 54 postmenopausal controls in Table 2. Similar results were obtained both including and excluding premenopausal women. IGF-I had moderate inverse associations with BMI and direct associations with IGF-II and IGFBP-3, and IGF-II had very strong positive correlation with IGFBP-3 and moderate positive correlation with GHBP. IGFBP-1 increased moderated with age, and showed modest but significant negative associations with BMI, leptin, and insulin. IGFBP-1 had positive correlation with GHBP, whereas IGFBP-3 and GHBP had a direct association. Both IGFBP-4 and IGFBP-6 were directly related to age and showed significant positive association with each other. GHBP showed weak negative correlation with age and positive correlations with BMI and IGFBP-4 (Table 2). Adjusting for age and BMI using partial correlations did not appreciably alter associations between biochemical variables, and similar measures were obtained when including the 74 breast cancer cases in calculating the correlation coefficient (data not shown).

Age- and multivariate-adjusted odds ratios (ORs) for all subjects are presented in Table 3. In age-adjusted models, higher tertile of GHBP was associated with a marginal $54 \%$ increased risk of breast cancer $(P=0.06)$. After adjusting further for BMI, this association intensified to a $77 \%$ increase in risk $(P=0.02)$. In multivariate models, including age, BMI, height, reproductive and family history, and mutually adjusting for components of the GH-IGF-IGFBP system, each tertile increase of GHBP conferred a 3.3-fold increase in breast cancer risk $(P<0.01)$. In addition, higher tertile of IGFBP-3 was significantly associated with an $81 \%$ reduced risk of breast cancer after multivariate adjustment. Results were similar when premenopausal women were excluded from the analysis (Table 4). In bivariate models, higher tertile of IGFBP-3 was marginally associated with a $44 \%$ decreased risk of breast cancer $(P=0.10)$. This association was somewhat strengthened after adjustment for classical breast cancer risk factors $(P=0.09)$. After mutually adjusting for the effects of the other components of the IGF-IGFBP system and hormones insulin and leptin, higher tertile of IGFBP-3 was significantly associated with a $77 \%$ 
Table 2 Correlation matrix for biochemical factors from Spearman partial correlation coefficients.

\begin{tabular}{|c|c|c|c|c|c|c|c|c|c|}
\hline & Insulin & Leptin & IGF-I & IGF-II & IGFBP-1 & IGFBP-3 & IGFBP-4 & IGFBP-6 & GHBP \\
\hline \multicolumn{10}{|c|}{ All controls $(n=76)$} \\
\hline Age & 0.06 & 0.06 & $-0.32^{\dagger}$ & -0.19 & 0.23 & $-0.25^{\star}$ & $0.35^{\dagger}$ & $0.43^{\dagger}$ & -0.02 \\
\hline BMI & $0.35^{\dagger}$ & $0.64^{\dagger}$ & $-0.38^{\dagger}$ & -0.02 & $-0.40^{\dagger}$ & -0.08 & $0.36^{\dagger}$ & 0.06 & $0.44^{\dagger}$ \\
\hline Insulin & & $0.265^{*}$ & -0.19 & -0.13 & $-0.33^{\dagger}$ & -0.17 & 0.08 & 0.05 & $0.36^{\dagger}$ \\
\hline Leptin & & & -0.22 & 0.20 & $-0.42^{\dagger}$ & 0.16 & $0.32^{\dagger}$ & -0.06 & $0.46^{\dagger}$ \\
\hline IGF-I & & & & $0.53^{\dagger}$ & -0.11 & $0.68^{\dagger}$ & $-0.32^{\dagger}$ & -0.05 & 0.04 \\
\hline IGF-II & & & & & -0.20 & $0.91^{\dagger}$ & 0.12 & $-0.24^{\star}$ & $0.46^{\dagger}$ \\
\hline IGFBP-1 & & & & & & -0.21 & -0.04 & 0.09 & $-0.58^{\dagger}$ \\
\hline IGFBP-3 & & & & & & & 0.03 & $-0.24^{*}$ & $0.41^{\dagger}$ \\
\hline IGFBP-4 & & & & & & & & $0.34^{\dagger}$ & $0.35^{\dagger}$ \\
\hline IGFBP-6 & & & & & & & & & -0.13 \\
\hline \multicolumn{10}{|c|}{ Postmenopausal $(n=54)$} \\
\hline Age & -0.15 & -0.15 & -0.17 & -0.27 & $0.52^{\dagger}$ & -0.22 & $0.35^{\dagger}$ & $0.52^{\dagger}$ & $-0.32^{\star}$ \\
\hline $\mathrm{BMI}$ & 0.27 & $0.70^{\dagger}$ & $-0.41^{\dagger}$ & 0.16 & $-0.47^{\dagger}$ & 0.11 & 0.25 & 0.03 & $0.41^{\dagger}$ \\
\hline Insulin & & 0.24 & -0.21 & -0.12 & $-0.33^{\star}$ & -0.14 & 0.01 & 0.07 & 0.26 \\
\hline Leptin & & & -0.18 & 0.20 & $-0.48^{\dagger}$ & 0.22 & 0.21 & -0.03 & $0.39^{\dagger}$ \\
\hline IGF-I & & & & $0.54^{\dagger}$ & -0.09 & $0.65^{\dagger}$ & -0.16 & -0.06 & 0.14 \\
\hline IGF-II & & & & & -0.25 & $0.91^{\dagger}$ & 0.21 & -0.16 & $0.52^{\dagger}$ \\
\hline IGFBP-1 & & & & & & -0.28 & -0.10 & 0.17 & $-0.56^{\dagger}$ \\
\hline IGFBP-3 & & & & & & & 0.15 & -0.14 & $0.53^{\dagger}$ \\
\hline IGFBP-4 & & & & & & & & $0.51^{\dagger}$ & $0.29^{\star}$ \\
\hline IGFBP-6 & & & & & & & & & -0.12 \\
\hline
\end{tabular}

${ }^{\star} P<0.05 ;{ }^{\dagger} P<0.01$. Spearman partial correlations based on data from control subjects. Partial correlations adjusting for age and BMI did not substantially alter associations among biochemical variables.

decreased risk and GHBP with a threefold increased risk of breast cancer ( $P=0.02$ for both, Table 4$)$. Excluding metastatic cases $(n=9)$ from the analysis and adjusting for the stage of disease did not substantially alter reported results for either all or postmenopausal subjects (not shown).

\section{Discussion}

In this hospital-based case-control study of predominantly postmenopausal women, we did not find a significant association of either IGF-I or IGF-II with risk of breast cancer, but demonstrated a protective role of

Table 3 Crude and multivariate mutually adjusted risk of breast cancer by tertiles of insulin, leptin, IGF-I, IGF-II, IGFBP-1, IGFBP-3, IGFBP-4, IGFBP-6, and GHBP.

\begin{tabular}{|c|c|c|c|c|c|}
\hline & OR $^{\mathbf{a}}(95 \% \mathrm{Cl})$ & OR $^{\mathbf{b}}(95 \% \mathrm{Cl})$ & OR $^{\mathbf{c}}(95 \% \mathrm{Cl})$ & OR $^{\mathbf{d}}(95 \% \mathrm{Cl})$ & OR $^{\mathbf{e}}(95 \% \mathrm{Cl})$ \\
\hline \multicolumn{6}{|l|}{ Hormones } \\
\hline Insulin & $0.99(0.65-1.51)$ & $1.06(0.68-1.65)$ & $1.09(0.68-1.74)$ & $0.78(0.43-1.42)$ & $0.60(0.30-1.19)$ \\
\hline$P$ value & 0.97 & 0.80 & 0.72 & 0.42 & 0.14 \\
\hline Leptin & $0.94(0.62-1.43)$ & $1.00(0.62-1.61)$ & $1.06(0.64-1.77)$ & $0.72(0.40-1.32)$ & $0.85(0.41-1.76)$ \\
\hline$P$ value & 0.94 & 0.99 & 0.82 & 0.29 & 0.67 \\
\hline \multicolumn{6}{|c|}{ Growth factors } \\
\hline IGF-I & $1.12(0.70-1.79)$ & $1.07(0.66-1.74)$ & $1.08(0.66-1.78)$ & $1.30(0.64-2.67)$ & $1.59(0.68-3.73)$ \\
\hline$P$ value & 0.65 & 0.77 & 0.75 & 0.47 & 0.29 \\
\hline IGF-II & $1.20(0.77-1.87)$ & $1.22(0.78-1.91)$ & $1.36(0.84-2.19)$ & $1.20(0.50-2.88)$ & $1.70(0.63-4.55)$ \\
\hline$P$ value & 0.43 & 0.39 & 0.98 & 0.69 & 0.29 \\
\hline \multicolumn{6}{|c|}{ Binding proteins } \\
\hline IGFBP-1 & $1.36(0.88-2.10)$ & $1.30(0.82-2.06)$ & $1.21(0.73-2.02)$ & $1.51(0.82-2.78)$ & $0.91(0.44-1.86)$ \\
\hline$P$ value & 0.16 & 0.26 & 0.46 & 0.19 & 0.79 \\
\hline IGFBP-3 & $0.79(0.51-1.21)$ & $0.78(0.51-1.21)$ & $0.81(0.52-1.26)$ & $0.37(0.15-0.96)$ & $0.19(0.06-0.58)$ \\
\hline$P$ value & 0.27 & 0.27 & 0.35 & 0.04 & $<0.01$ \\
\hline IGFBP-4 & $0.89(0.57-1.41)$ & $0.96(0.58-1.59)$ & $0.89(0.52-1.51)$ & $1.21(0.65-2.25)$ & $0.91(0.43-1.92)$ \\
\hline$P$ value & 0.63 & 0.88 & 0.66 & 0.55 & 0.80 \\
\hline IGFBP-6 & $0.79(0.57-1.10)$ & $0.79(0.57-1.10)$ & $0.74(0.52-1.05)$ & $0.98(0.66-1.46)$ & $0.80(0.50-1.28)$ \\
\hline$P$ value & 0.16 & 0.17 & 0.09 & 0.92 & 0.36 \\
\hline GHBP & $1.54(0.98-2.41)$ & $1.77(1.09-2.89)$ & $2.13(1.23-3.68)$ & $2.52(1.26-5.02)$ & $3.32(1.49-7.41)$ \\
\hline$P$ value & 0.06 & 0.02 & $<0.01$ & $<0.01$ & $<0.01$ \\
\hline
\end{tabular}

${ }^{\text {aAdjusted for age. }}$

${ }^{\mathrm{b}}$ Adjusted for age and BMI.

${ }^{\mathrm{c}}$ Adjusted for age, BMI, height, age at menarche, age at menopause, nulliparous status, and family history of breast cancer.

dMutually adjusted IGF-I, IGF-II, IGFBP-1, IGFBP-3, GHBP, IGFBP-4, IGFBP-6, insulin, and leptin.

${ }^{\text {e}}$ Mutually adjusted IGF-I, IGF-II, IGFBP-1, IGFBP-3, GHBP, IGFBP-4, IGFBP-6, insulin, and leptin; controlling additionally for age, BMI, and height; age at menarche, age at menopause, nulliparous status, and family history of breast cancer. 
Table 4 Crude and multivariate mutually adjusted risk of postmenopausal breast cancer by tertiles of insulin, leptin, IGF-I, IGF-II, IGFBP-1, IGFBP-3, IGFBP-4, IGFBP-6, and GHBP.

\begin{tabular}{|c|c|c|c|c|c|}
\hline & OR $^{\mathbf{a}}(95 \% \mathrm{Cl})$ & OR $^{\mathbf{b}}(95 \% \mathrm{Cl})$ & OR $^{\mathbf{c}}(95 \% \mathrm{Cl})$ & $\mathbf{O R}^{\mathbf{d}}(95 \% \mathrm{Cl})$ & OR $^{\mathbf{e}}(95 \% \mathrm{Cl})$ \\
\hline \multicolumn{6}{|l|}{ Hormones } \\
\hline Insulin & $1.03(0.65-1.61)$ & $1.06(0.67-1.69)$ & $1.10(0.68-1.77)$ & $0.75(0.41-1.35)$ & $0.64(0.33-1.22)$ \\
\hline$P$ value & 0.91 & 0.81 & 0.71 & 0.33 & 0.17 \\
\hline Leptin & $0.99(0.61-1.62)$ & $1.07(0.61-1.89)$ & $1.13(0.61-2.09)$ & $0.74(0.38-1.43)$ & $0.91(0.41-2.01)$ \\
\hline$P$ value & 0.96 & 0.80 & 0.69 & 0.37 & 0.82 \\
\hline \multicolumn{6}{|c|}{ Growth factors } \\
\hline IGF-I & $0.82(0.50-1.35)$ & $0.80(0.48-1.32)$ & $0.76(0.45-1.30)$ & $1.15(0.55-2.43)$ & $1.20(0.54-2.69)$ \\
\hline$P$ value & 0.44 & 0.78 & 0.32 & 0.71 & 0.65 \\
\hline IGF-II & $1.00(0.61-1.65)$ & $1.03(0.62-1.70)$ & $1.00(0.58-1.72)$ & $1.31(0.46-3.71)$ & $1.68(0.53-5.34)$ \\
\hline$P$ value & 0.99 & 0.92 & 0.99 & 0.61 & 0.38 \\
\hline \multicolumn{6}{|c|}{ Binding proteins } \\
\hline IGFBP-1 & $1.23(0.72-2.10)$ & $1.16(0.66-2.04)$ & $1.19(0.66-2.13)$ & $1.21(0.63-2.34)$ & $0.77(0.35-1.67)$ \\
\hline$P$ value & 0.44 & 0.60 & 0.57 & 0.57 & 0.50 \\
\hline IGFBP-3 & $0.66(0.41-1.08)$ & $0.67(0.41-1.09)$ & $0.64(0.38-1.08)$ & $0.32(0.11-0.90)$ & $0.23(0.07-0.75)$ \\
\hline$P$ value & 0.10 & 0.11 & 0.09 & 0.03 & 0.02 \\
\hline IGFBP-4 & $0.92(0.54-1.58)$ & $0.98(0.55-1.74)$ & $0.99(0.54-1.82)$ & $1.32(0.67-2.63)$ & $1.14(0.53-2.42)$ \\
\hline$P$ value & 0.77 & 0.95 & 0.98 & 0.42 & 0.74 \\
\hline IGFBP-6 & $0.83(0.57-1.20)$ & $0.83(0.57-1.20)$ & $0.80(0.54-1.18)$ & $1.15(0.73-1.80)$ & $0.96(0.58-1.60)$ \\
\hline$P$ value & 0.32 & 0.32 & 0.26 & 0.53 & 0.88 \\
\hline GHBP & $1.22(0.91-1.64)$ & $1.75(0.95-3.24)$ & $1.78(0.95-3.36)$ & $2.28(0.98-5.30)$ & $3.08(1.16-8.21)$ \\
\hline$P$ value & 0.18 & 0.07 & 0.07 & 0.05 & 0.02 \\
\hline
\end{tabular}

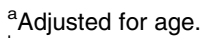

${ }^{\mathrm{b}}$ Adjusted for age and BMI.

${ }^{\mathrm{C}}$ Adjusted for age, BMI, height, age at menarche, age at menopause, nulliparous status, and family history of breast cancer.

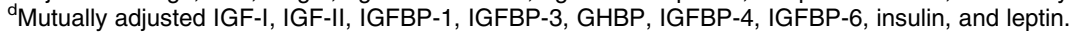

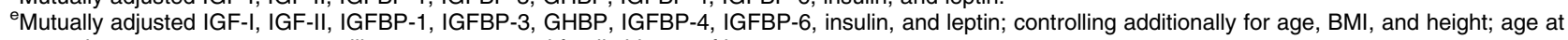
menarche, age at menopause, nulliparous status, and family history of breast cancer.

IGFBP-3. Our results also suggest novel findings of increased risk for breast cancer with higher levels of GHBP and indicate that IGFBP-1, IGFBP-4, and IGFBP6 are not significantly associated with breast cancer risk. The association with GHBP persisted after mutual adjustment for the components of the IGF-IGFBP axis, implying a potential role of either GHBP per se or the status of the GH receptor in breast cancer pathophysiology independent of the IGF system. These analyses also took into account potential effects of hyperinsulinemia, by including insulin and leptin, which we show to have no independent associations with breast cancer of their own accord.

Serum IGF-I appears to be associated with risk of breast cancer among premenopausal women $(7,10,12$, $13,15,17,24,25)$, but no similar association has been found among postmenopausal women $(10,26)$. Several explanations for this dichotomy have been proposed. One mechanism may include the induction IGF-I production by higher estrogen levels in premenopausal women (9). This explains the inverse correlation between serum IGF-I and age $(r=-0.33$ in our study, Table 2), and it is plausible that these increased levels would exert a greater effect on the development of premenopausal breast cancer. Premenopausal breast cancer has previously been shown not to be associated with high BMI, while postmenopausal breast cancer has been linked with obesity (27). In our study, IGF-I was inversely associated with BMI $(r=-0.38)$. Thus, since our study population consisted primarily of postmenopausal women, it is not surprising that we detected no relationship between IGF-I and breast cancer risk. We also did not find any association between IGF-II and risk of breast cancer, as has been reported previously (7). However, evidence from animal and cell line experiments examining the role of IGF-II in carcinogenesis indicates increased rates of malignancies, including breast tumors (28-33), and results from one case-control study found a positive association between IGF-II and ER-positive but not ER-negative breast cancer among postmenopausal women (9). We report a nonsignificant increase in risk by $\sim 70 \%$, and thus a potential role of IGF-II in pre- and postmenopausal breast cancer needs to be studied further.

More than $99 \%$ of circulating IGFs are bound to IGFBPs. IGFBPs not only regulate IGF action and bioavailability, but also appear to mediate IGFindependent actions, including inhibition or enhancement of cell growth and induction of apoptosis (21). The most thoroughly studied IGFBP in relation to breast cancer has been IGFBP-3. Several studies have reported a direct relationship between IGFBP-3 and risk of breast cancer in premenopausal women $(8,10-$ $12,14,17)$; however, results from observational studies have been particularly inconsistent among postmenopausal women $(9,11,12,14,26)$. Our data support an inverse relationship between IGFBP-3 and breast cancer. Beneficial actions of IGFBP-3 may include anti-proliferative effects and induction of apoptosis, both through sequestration of IGF-I and 
via IGF-independent effects (34). It is also possible that cleaved IGFBP-3 fragments may either promote or inhibit tumor growth (35). We have used a previously validated and reliable assay $(22,23)$ to measure IGFBP-3. Other IGFBPs have been studied less extensively. We did not find any significant independent association between risk of breast cancer and IGFBP-1, as reported previously $(12,15,26)$, nor IGFBP-4 or IGFBP-6, which have not been evaluated prior in breast cancer patients.

Since GH increases serum IGF-I levels, concern has been raised regarding its possible role in breast cancer. Some studies have identified an association between acromegaly and overall cancer risk (18-20), but others found no such association $(36,37)$. Moreover, a recent interventional study showed that human GH treatment induced mammary gland hyperplasia in aging animals, and this effect was not mediated through IGF-I (38). It has also been demonstrated that human GH can act in an autocrine/paracrine manner in human mammary carcinoma cells to promote proliferation and transcriptional activation $(39,40)$. A recent study (16) of premenopausal women failed to find an association between breast cancer and $\mathrm{GH}$ but did not examine GHBP. GH itself is a difficult marker to study because of its pulsatile secretion and circadian variability and heterogeneity of available assays, which can increase the complexity of GH quantification especially at the low range of GH concentrations (41-46). Thus, a single serum GH determination is not adequate for assessing GH levels in epidemiology studies. GHBP reflects GH receptor status, and circulating GHBP levels are inversely related to $\mathrm{GH}$ levels in healthy subjects or patients with acromegaly or GH deficiency. We used this marker in our study and found a more than threefold increased risk of breast cancer for women in higher tertiles of serum GHBP concentration. This risk estimate remained significant after adjustment for other components of the IGF system. Further studies are needed to confirm an IGF-independent relationship between the GHBP and the risk for breast cancer and to study the potential underlying mechanisms.

In summary, our study is the first to examine simultaneously the role of components of the GH-IGFIGFBP axis that can be reliably measured using current technology in the pathogenesis of breast cancer. Advantages of the study include the simultaneous measurement of biochemical variables in a standardized and established manner and the blinding of laboratory personnel to case-control status. In addition, we were able to examine the effect of each component adjusting only for classical breast cancer risk factors and also were able to detect associations independent of other GH-IGF components in mutually adjusted models (Table 3), a matter of particular importance given the high colinearity between these factors (Table 2). Of particular importance, negative confounding due to positive correlations between IGFBP-3 and GHBP attenuated the associations of both variables with breast cancer toward the null in crude models. After mutual adjustment, significant negative association with IGFBP-3 and positive association with GHBP became apparent. The study was relatively heterogeneous with respect to age, but we adjusted for this potential confounder in statistical analyses. The results of our study likely apply most closely to women with postmenopausal breast cancer and may not be as applicable to premenopausal women. Our results do not appear to be affected by severity of breast cancer, as similar associations were observed whether excluding late-stage cancers or taking into account stage of breast cancer in statistical analyses. A separate consideration is the fact that blood samples were not obtained prospectively, which precludes the establishment of causation. In spite of these limitations, our results are largely consistent with previous findings from prospective studies on the role of IGF-I, IGF-II, IGFBP-1, and IGFBP-3 in postmenopausal breast cancer. In addition, we have demonstrated for the first time that GHBP significantly increased breast cancer risk independently of the IGF system. We also show that IGFBP-4 and IGFBP-6, which have not been studied prior in breast cancer, appear to have no significant association with disease risk, although this remains to be verified by larger studies. The cross-sectional nature and wide scope of biochemical factors explored provide a solid hypothesis-generating body of data in this area of research. Further matched case-control, prospective, and interventional studies are needed to confirm and/or extend our results and to provide insight into the biological mechanisms of the GH, GHBP, and the IGF system in breast cancer pathophysiology.

\section{Acknowledgements}

We thank Dr Maria Bountina for valuable contributions to sample collection. Dr Christos Mantzoros is a recipient of a Wilhelm Bessel Award by the Humboldt Foundation. This study was supported in part by grantin-aid from Tanita Corporation.

\section{References}

1 Burger AM, Leyland-Jones B, Banerjee K, Spyropoulos DD \& Seth AK. Essential roles of IGFBP-3 and IGFBP-rP1 in breast cancer. European Journal of Cancer 200541 1515-1527.

2 Khosravi MJ, Diamandi A, Mistry J, Krishna RG \& Khare A. Acidlabile subunit of human insulin-like growth factor-binding protein complex: measurement, molecular, and clinical evaluation. Journal of Clinical Endocrinology and Metabolism $1997 \mathbf{8 2}$ 3944-3951.

3 Baumann G. Growth hormone binding protein. The soluble growth hormone receptor. Minerva Endocrinologica 200227 265-276. 
4 Barnard R \& Waters MJ. The serum growth hormone binding protein: pregnant with possibilities. Journal of Endocrinology 1997 $1531-14$.

5 Amit T, Youdim MB \& Hochberg Z. Clinical review 112: does serum growth hormone $(\mathrm{GH})$ binding protein reflect human $\mathrm{GH}$ receptor function? Journal of Clinical Endocrinology and Metabolism 200085 927-932.

6 Baumann G, Shaw MA \& Amburn K. Circulating growth hormone binding proteins. Journal of Endocrinological Investigation 199417 67-81.

7 Allen NE, Roddam AW, Allen DS, Fentiman IS, Dos SSI, Peto J, Holly JM \& Key TJ. A prospective study of serum insulin-like growth factor-I (IGF-I), IGF-II, IGF-binding protein-3 and breast cancer risk. British Journal of Cancer 200592 1283-1287.

8 Bohlke K, Cramer DW, Trichopoulos D \& Mantzoros CS. Insulinlike growth factor-I in relation to premenopausal ductal carcinoma in situ of the breast. Epidemiology $19989570-573$.

9 Gronbaek H, Flyvbjerg A, Mellemkjaer L, Tjonneland A, Christensen J, Sorensen HT \& Overvad K. Serum insulin-like growth factors, insulin-like growth factor binding proteins, and breast cancer risk in postmenopausal women. Cancer Epidemiology, Biomarkers and Prevention 200413 1759-1764.

10 Hankinson SE, Willett WC, Colditz GA, Hunter DJ, Michaud DS, Deroo B, Rosner B, Speizer FE \& Pollak M. Circulating concentrations of insulin-like growth factor-I and risk of breast cancer. Lancet 1998351 1393-1396.

11 Kaaks R, Lundin E, Rinaldi S, Manjer J, Biessy C, Soderberg S, Lenner P, Janzon L, Riboli E, Berglund G \& Hallmans G. Prospective study of IGF-I, IGF-binding proteins, and breast cancer risk, in northern and southern Sweden. Cancer Causes and Control: CCC 200213 307-316.

12 Krajcik RA, Borofsky ND, Massardo S \& Orentreich N. Insulin-like growth factor I (IGF-I), IGF-binding proteins, and breast cancer. Cancer Epidemiology, Biomarkers and Prevention $2002 \quad 11$ 1566-1573.

13 Rinaldi S, Kaaks R, Zeleniuch-Jacquotte A, Arslan AA, Shore RE, Koenig KL, Dossus L, Riboli E, Stattin P, Lukanova A \& Toniolo P. Insulin-like growth factor-I, IGF binding protein-3, and breast cancer in young women: a comparison of risk estimates using different peptide assays. Cancer Epidemiology, Biomarkers and Prevention 200514 48-52.

14 Rinaldi S, Peeters PH, Berrino F, Dossus L, Biessy C, Olsen A, Tjonneland A, Overvad K, Clavel-Chapelon F, Boutron-Ruault MC, Tehard B, Nagel G, Linseisen J, Boeing H, Lahmann PH, Trichopoulou A, Trichopoulos D, Koliva M, Palli D, Panico S, Tumino R, Sacerdote C, van Gils CH, van Noord P, Grobbee DE, Bueno-de-Mesquita HB, Gonzalez CA, Agudo A, Chirlaque MD, Barricarte A, Larranaga N, Quiros JR, Bingham S, Khaw KT, Key T, Allen NE, Lukanova A, Slimani N, Saracci R, Riboli E \& Kaaks R. IGF-I, IGFBP-3 and breast cancer risk in women: the European Prospective Investigation into Cancer and Nutrition (EPIC). Endocrine-Related Cancer 200613 593-605.

15 Schernhammer ES, Holly JM, Pollak MN \& Hankinson SE. Circulating levels of insulin-like growth factors, their binding proteins, and breast cancer risk. Cancer Epidemiology, Biomarkers and Prevention 200514 699-704.

16 Schernhammer ES, Holly JM, Hunter DJ, Pollak MN \& Hankinson SE. Insulin-like growth factor-I, its binding proteins (IGFBP-1 and IGFBP-3), and growth hormone and breast cancer risk in The Nurses Health Study II. Endocrine-Related Cancer 2006 13 583-592.

17 Toniolo P, Bruning PF, Akhmedkhanov A, Bonfrer JM, Koenig KL, Lukanova A, Shore RE \& Zeleniuch-Jacquotte A. Serum insulinlike growth factor-I and breast cancer. International Journal of Cancer $2000 \mathbf{8 8} 828-832$.

18 Ron E, Gridley G, Hrubec Z, Page W, Arora S \& Fraumeni JF Jr. Acromegaly and gastrointestinal cancer. Cancer $1991 \mathbf{6 8}$ 1673-1677.

19 Popovic V, Damjanovic S, Micic D, Nesovic M, Djurovic M, Petakov M, Obradovic S, Zoric S, Simic M, Penezic Z \&
Marinkovic J. Increased incidence of neoplasia in patients with pituitary adenomas. The Pituitary Study Group. Clinical Endocrinology $1998 \mathbf{4 9} 441-445$.

20 Bengtsson BA, Eden S, Ernest I, Oden A \& Sjogren B. Epidemiology and long-term survival in acromegaly. A study of 166 cases diagnosed between 1955 and 1984. Acta Medica Scandinavica 1988223 327-335.

21 Ferry RJ Jr, Cerri RW \& Cohen P. Insulin-like growth factor binding proteins: new proteins, new functions. Hormone Research 199951 53-67.

22 Skalkidou A, Petridou E, Papathoma E, Salvanos H, Kedikoglou S, Chrousos G \& Trichopoulos D. Determinants and consequences of major insulin-like growth factor components among full-term healthy neonates. Cancer Epidemiology, Biomarkers and Prevention $200312860-865$.

23 Petridou E, Koukoulomatis P, Alexe DM, Voulgaris Z, Spanos E \& Trichopoulos D. Endometrial cancer and the IGF system: a casecontrol study in Greece. Oncology 200364 341-345.

24 Sugumar A, Liu YC, Xia Q, Koh YS \& Matsuo K. Insulin-like growth factor (IGF)-I and IGF-binding protein 3 and the risk of premenopausal breast cancer: a meta-analysis of literature. International Journal of Cancer $2004111293-297$.

25 Bruning PF, Van Doorn J, Bonfrer JM, Van Noord PA, Korse CM, Linders TC \& Hart AA. Insulin-like growth-factor-binding protein 3 is decreased in early-stage operable pre-menopausal breast cancer. International Journal of Cancer 199562 266-270.

26 Keinan-Boker L, Bueno de Mesquita HB, Kaaks R, van Gils CH, Van Noord PA, Rinaldi S, Riboli E, Seidell JC, Grobbee DE \& Peeters PH. Circulating levels of insulin-like growth factor I, its binding proteins -1,-2, -3, C-peptide and risk of postmenopausal breast cancer. International Journal of Cancer 2003106 90-95.

27 Harris JR, Lippman ME, Veronesi U \& Willett W. Breast cancer (1). New England Journal of Medicine 1992327 319-328.

28 Paik S. Expression of IGF-I and IGF-II mRNA in breast tissue. Breast Cancer Research and Treatment 199222 31-38.

29 Osborne CK, Coronado EB, Kitten LJ, Arteaga CI, Fuqua SA, Ramasharma K, Marshall M \& Li CH. Insulin-like growth factor-II (IGF-II): a potential autocrine/paracrine growth factor for human breast cancer acting via the IGF-I receptor. Molecular Endocrinology $198931701-1709$.

30 Rogler CE, Yang D, Rossetti L, Donohoe J, Alt E, Chang CJ, Rosenfeld R, Neely K \& Hintz R. Altered body composition and increased frequency of diverse malignancies in insulin-like growth factor-II transgenic mice. Journal of Biological Chemistry 1994269 13779-13784.

31 Bates P, Fisher R, Ward A, Richardson L, Hill DJ \& Graham CF. Mammary cancer in transgenic mice expressing insulin-like growth factor II (IGF-II). British Journal of Cancer $1995 \mathbf{7 2}$ 1189-1193.

32 Schirmacher P, Held WA, Yang D, Chisari FV, Rustum Y \& Rogler CE. Reactivation of insulin-like growth factor II during hepatocarcinogenesis in transgenic mice suggests a role in malignant growth. Cancer Research 199252 2549-2556.

33 Christofori G, Naik P \& Hanahan D. A second signal supplied by insulin-like growth factor II in oncogene-induced tumorigenesis. Nature 1994369 414-418.

34 Firth SM \& Baxter RC. Cellular actions of the insulin-like growth factor binding proteins. Endocrine Reviews 200223 824-854.

35 Baxter RC. What is the significance of IGF-binding protein-3 proteolysis in the circulation? Journal of Clinical Endocrinology and Metabolism 200186 5087-5088.

36 Delhougne B, Deneux C, Abs R, Chanson P, Fierens H, LaurentPuig P, Duysburgh I, Stevenaert A, Tabarin A \& Delwaide J. The prevalence of colonic polyps in acromegaly: a colonoscopic and pathological study in 103 patients. Journal of Clinical Endocrinology and Metabolism $1995 \mathbf{8 0} 3223-3226$.

37 Ladas SD, Thalassinos NC, Ioannides G \& Raptis SA. Does acromegaly really predispose to an increased prevalence of gastrointestinal tumours? Clinical Endocrinology $1994 \mathbf{4 1}$ 597-601. 
38 Ng ST, Zhou J, Adesanya OO, Wang J, LeRoith D \& Bondy CA. Growth hormone treatment induces mammary gland hyperplasia in aging primates. Nature Medicine 19973 1141-1144.

39 Kaulsay KK, Mertani HC, Tornell J, Morel G, Lee KO \& Lobie PE. Autocrine stimulation of human mammary carcinoma cell proliferation by human growth hormone. Experimental Cell Research 1999250 35-50.

40 Kaulsay KK, Zhu T, Bennett W, Lee KO \& Lobie PE. The effects of autocrine human growth hormone (hGH) on human mammary carcinoma cell behavior are mediated via the hGH receptor. Endocrinology 2001142 767-777.

41 Banfi G, Marinelli M, Casari E, Murone M \& Bonini P. Isotopic and nonisotopic assays for measuring somatotropin compared: re-evaluation of cutoff value in provocative tests. Clinical Chemistry $199137273-276$.

42 Bowsher RR, Apathy JM, Ferguson AL, Riggin RM \& Henry DP. Cross-reactivity of monomeric and dimeric biosynthetic human growth hormone in commercial immunoassays. Clinical Chemistry $199036362-366$.
43 Celniker AC, Chen AB, Wert RM Jr \& Sherman BM. Variability in the quantitation of circulating growth hormone using commercial immunoassays. Journal of Clinical Endocrinology and Metabolism $198968469-476$.

44 Markkanen H, Pekkarinen T, Valimaki MJ, Alfthan H, KauppinenMakelin R, Sane T \& Stenman UH. Effect of sex and assay method on serum concentrations of growth hormone in patients with acromegaly and in healthy controls. Clinical Chemistry $2006 \mathbf{5 2} 468-473$.

45 Jansson C, Boguszewski C, Rosberg S, Carlsson L \& AlbertssonWikland K. Growth hormone (GH) assays: influence of standard preparations, GH isoforms, assay characteristics, and GH-binding protein. Clinical Chemistry 199743 950-956.

46 L'Hermite-Baleriaux M, Copinschi G \& Van Cauter E. Growth hormone assays: early to latest test generations compared. Clinical Chemistry 199642 1789-1795.

Received 29 November 2006

Accepted 30 November 2006 